\title{
Are human rights regressing on almost every front? Confronting some of the current social inclusion challenges
}

In her final week as Australia's Human Rights Commissioner in July 2017, Professor Gillian Triggs noted that human rights in Australia are regressing on almost all fronts, having suggested the nation's government appeared to be ideologically opposed to human rights (Triggs, 2017, as cited in Zlesak, 2017). The statement should stimulate discussion among decision-makers, academia, the media and society, more broadly - in the same way we hope that one of the main themes emerging in this edition about the relative disadvantage of first Australians promotes further consideration and action. Despite her warnings about the decline in human rights and social justice, however, and the significant expansion of executive powers in Australia, unsurprisingly, we have all continued-on in our busy lives and the 24/7 news cycle has rolled on too.

The reality across much of the world is that social inclusion and exclusion are no longer just applicable to diverse minority groups and others on society's margins for whom the climate, as suggested by Professor Trigg, is far from conducive. Rising inequalities and levels of relative poverty, particularly in Australia and other high-income countries, are resulting in more working families or 'average' citizens experiencing the effects of relative deprivation and the associated decline in economic and social participation (Harris, in press). Fortunately, new insights and areas of good practice continue to be identified - as many of the researchers published in this edition demonstrate.

The first paper, by Opuku, highlights the progress being made in inclusive education practices in Ghana. It is now more than ten years since an inclusive education program was piloted in Ghana, and perceived achievements and challenges were explored from the perspective of special educators and education officials across two regions $(n=60)$. Findings suggests the main achievement has been the subsequent expansion of the program to 1486 schools, including in some of the most deprived regions of Ghana. It should be noted, however, that there were some marked differences observed from the perspectives of officials who tended to believe the program had not been successfully implemented, and educators, who were more optimistic yet also acknowledged there were implementation issues. A number of challenges were identified in relation to funding, access to resources, teacher training and the accessibility of school environments. The paper identifies opportunities for the further development of inclusive education in Ghana, including the need for improved coordination and more research to inform implementation issues.

The inclusive education theme is further demonstrated in the context of the second paper by Hamilton. The explorative study of beginning teachers' attitudes $(n=74)$ was undertaken in the Waikato region of New Zealand. The research examining participants' knowledge of previous institutionalised practices at a large regional facility, found that most had no awareness of the hospital, how it operated and therefore its impacts on people with disabilities. Hamilton suggests the insights of the third of those who were aware of the institution may be indicative of commencing teachers' beliefs about inclusive education. The implications for beginning teacher programs are discussed, as is the need to raise awareness of the legacy of past practices, more broadly.

The third paper presents the results of a systematic review of the literature by Lakhani, Cullen and Townsend, examining the disproportionate costs of Indigenous peoples with disabilities compared to other Australians with a disability. The paucity of research on this topic was reflected in the lack of available articles to meet search criteria. The very limited research that was available, however, is discussed and used to identify key gaps in the evidence base and future research needs. The possible implications for service delivery are 
also discussed including the need for culturally appropriate responses (and assessment) from health care and other service providers; provision of local, integrated care; better engagement with families; and more awareness raising about disability services, more broadly.

The fourth paper in this edition examines the need to improve access to legal support for human rights issues, which Curran suggests are not well understood in the community. Furthermore, people often lack the confidence and capacity to seek, and ultimately achieve, some justice. In this context, secondary law consultations (e.g. with intermediaries, referral agencies) are seen to be effective in identifying and responding to human rights issues which may otherwise go unacknowledged, leading to a range of adverse health and related outcomes. This conclusion is supported by practice experiences and the results of research undertaken across urban and rural settings in Australia. This paper is considered highly relevant given the systemic discrimination faced by first Australians, as highlighted in the context of incarcerations that are more than 22 times higher than for non-Indigenous Australians in some states, and the proportion of Indigenous children in detention up to 58 times greater on a comparative basis (Martin, 2015). Curran nevertheless notes the utility of secondary law consultations in promoting justice for human rights issues, and ultimately, greater social justice too.

Further good practice opportunities are identified in the context of redressing Indigenous education and employment disadvantages, as identified by Brown. The results of the evaluation of the 'Building Family Opportunities Program' (BFO) are based on three years of survey data collected with 110 participating families and interviews with a smaller sample of job seekers and case managers. The novel South Australian program, based on a strengths-based, "life-first" approach recognising the importance of social and emotional support for whole families, demonstrates the value of culturally safe and respectful ways of working. Indeed, the identified increases in engagement in education and/or employment due to participating in the program, provides further evidence that community-based and strengths-based approaches to Indigenous issues are effective in producing immediate benefits and need to be further developed as part of efforts to "close the gap" in education and employment outcomes in Australia.

The final paper in this edition identifies the need for more research and collaborative action to redress the effects of social exclusion on health and wellbeing. In noting the significance of the social determinants of health and failure to redress health inequalities, Briggs and Harris clarify and discuss the importance of social inclusion and exclusion on health, and related concepts, social participation and social capital. How we see ourselves in relation to others, (something we learn at the earliest of ages), has a profound influence on our identity, opportunities, choices, stress responses, and our life outcomes and wellbeing generally (e.g. Harris, in press), yet the recognition of this remains limited. The proliferation of sociological/psychological concepts and different perspectives or lenses used by researchers over time to identify and analyse the many complexities associated with social and epidemiological research, potentially confusing or diffusing understandings of the influence of social factors; presents key challenges to the quest to galvanise and mobilise action. The article therefore usefully synthesises some of the different concepts used in the literature implicating the social determinants of health. While, reasserting the value and benefits of participatory and empowerment based approaches on health outcomes, critical theory is invoked when calling for the focus on participatory interventions to be matched by significant structural reforms if decision-makers are serious about changing the status quo.

Recent editions have noted the need for greater urgency; more awareness raising, advocacy and action; and further research to identify and inform the implementation of more inclusive policies and practices around the world. To this end, the Journal sent out a call for papers for a special edition focussed on the (broad) topic of 'social inclusion and health'. Despite 
receiving some interest, we will not be able to proceed with a dedicated special edition on this topic for our next issue. We do, however, look forward to publishing these and other papers on this topic in future editions.

In 2018, the Journal will be moving to a digital publishing platform to expand opportunities to further promote greater insight, research and practice wisdom on social inclusion issues. We will be welcoming creative, digitally rich submissions, including photography, video content, and traditional articles. The Journal is committed to continuing our peer-review publication with issues twice each year, but we will also feature monthly content through our interactive, engaging digital platform. We trust this will enable us to share more diverse perspectives and research findings on social inclusion and exclusion issues in the future.

\section{Paul Harris PhD}

Editor

School of Human Services and Social Work

Menzies Health Institute Queensland

Griffith University

\section{References}

Harris, P. (in press). Poverty and disadvantage among children and families. In Serr, K. Thinking about Poverty (4 ${ }^{\text {th }}$ Edition). Sydney: The Federation Press.

Martin, W. (2015). Indigenous Incarceration Rates: Strategies for much needed reform. Brief, 42(5), 8-13. Retrieved from:

http://search.informit.com.au.libraryproxy.griffith.edu.au/documentSummary; $\mathrm{dn}=4608$ 90674487308;res=IELAPA

Slezak, M. (2017). Gillian Triggs: Australian government 'ideologically opposed to human rights'. The Guardian, Australian Edition, Wednesday 26 July, 2017.Retrieved from: https://www.theguardian.com/australia-news/2017/jul/26/gillian-triggs-australiangovernment-ideologically-opposed-to-human-rights 